\title{
Atypical feeding of woodpeckers, crows and redstarts on mass-swarming Hydropsyche pellucidula caddisflies attracted to glass panes
}

\author{
Ádám Pereszlényi ${ }^{1,2}$ • Gábor Horváth ${ }^{2}$ • György Kriska ${ }^{3,4}$
}

(C) Springer Science+Business Media New York 2017

\begin{abstract}
Artificial shiny dark objects reflecting horizontally polarized light (e.g. asphalt roads, black cars, solar panels) can attract polarotactic aquatic insects in mass. Glass buildings on the riverside also lure swarming caddisflies emerging from the river. These caddisfly swarms are a temporary rich food source for certain bird species, such as white wagtails (Motacilla alba), house sparrows (Passer domesticus), magpies (Pica pica) and great tits (Parus major). We report here about our observation of great spotted woodpeckers (Dendrocopos major), hooded crows (Corvus cornix) and black redstarts (Phoenicurus ochruros) feeding atypically on Hydropsyche pellucidula caddisflies swarming at glass buildings placed on the shore of the river Danube in Budapest (Hungary).
\end{abstract}

Keywords Great spotted woodpecker - Dendrocopos major . Hooded crow $\cdot$ Corvus cornix $\cdot$ Black redstart $\cdot$ Phoenicurus ochruros $\cdot$ Caddisfly $\cdot$ Hydropsyche pellucidula $\cdot$ Feeding behaviour $\cdot$ Glass building $\cdot$ Light polarization

Electronic supplementary material The online version of this article (doi:10.1007/s11252-017-0672-3) contains supplementary material, which is available to authorized users.

Ádám Pereszlényi

adam.peresz@gmail.com

1 Department of Zoology, Bird Collection, Hungarian Natural History Museum, Ludovika tér 2-6, Budapest H-1083, Hungary

2 Environmental Optics Laboratory, Department of Biological Physics, Eötvös University, Pázmány sétány 1, Budapest H-1117, Hungary

3 Group for Methodology of Biology Teaching, Biological Institute, Eötvös University, Pázmány sétány 1, Budapest H-1117, Hungary

4 MTA Centre for Ecological Research, Danube Research Institute, Karolina út 29-31, Budapest H-1113, Hungary

\section{Introduction}

Aquatic insects recognize water surfaces by means of the horizontal polarization of water-reflected light (Schwind 1991, 1995; Horváth and Csabai 2014). Therefore, these insects are polarotactic, that is they are attracted to horizontally polarized light. Artificial objects reflecting such light (e.g. asphalt roads, black cars, solar panels) often deceive and attract polarotactic aquatic insects (Horváth et al. 2009). The females of these insects look for water to lay their eggs after they are fertilized. These females can oviposit onto horizontally polarizing artificial objects instead of water surfaces (Kriska et al. 1998, 2006). This phenomenon is well documented for the caddisfly Hydropsyche pellucidula swarming prior to sunset around glass buildings (Fig. 1) placed on the riverside (Kriska et al. 2008; Malik et al. 2008): In the first stage of swarming, buildings with their darker silhouette against the brighter sky background function as swarming markers for caddisflies emerging from the river Danube. Later, female caddisflies lay their eggs on darker glass panes reflecting horizontally polarized light (Fig. 2).

In 2006-2010, we have observed that the mass of $H$. pellucidula caddisflies swarming at glass buildings is an exploitable food source for white wagtails (Motacilla alba), house sparrows (Passer domesticus), magpies (Pica pica) and great tits (Parus major) (Horváth et al. 2009; Robertson et al. 2010). These birds captured and consumed the caddisflies flying around the buildings and landed on the glass panes (Fig. 3). In 2014 and 2016, we observed a male and a female great spotted woodpecker (Dendrocopos major) to hunt for H. pellucidula around the glass buildings (Fig. 4a-d, Supplementary Video Clips 1-2). In 2016 we observed pairs of black redstart (Phoenicurus ochruros) and hooded crow (Corvus cornix) feeding on $H$. pellucidula (Fig. 4e-f). We report here briefly about these observations and compare 
Fig. 1 The glass building of the Faculty of Natural Sciences of the Eötvös University in Budapest, Hungary. The lower third of the building is covered with red brickwork, while the remaining part is covered with shiny glass panels (dark grey, light grey and windows) and 14 columns of bricks

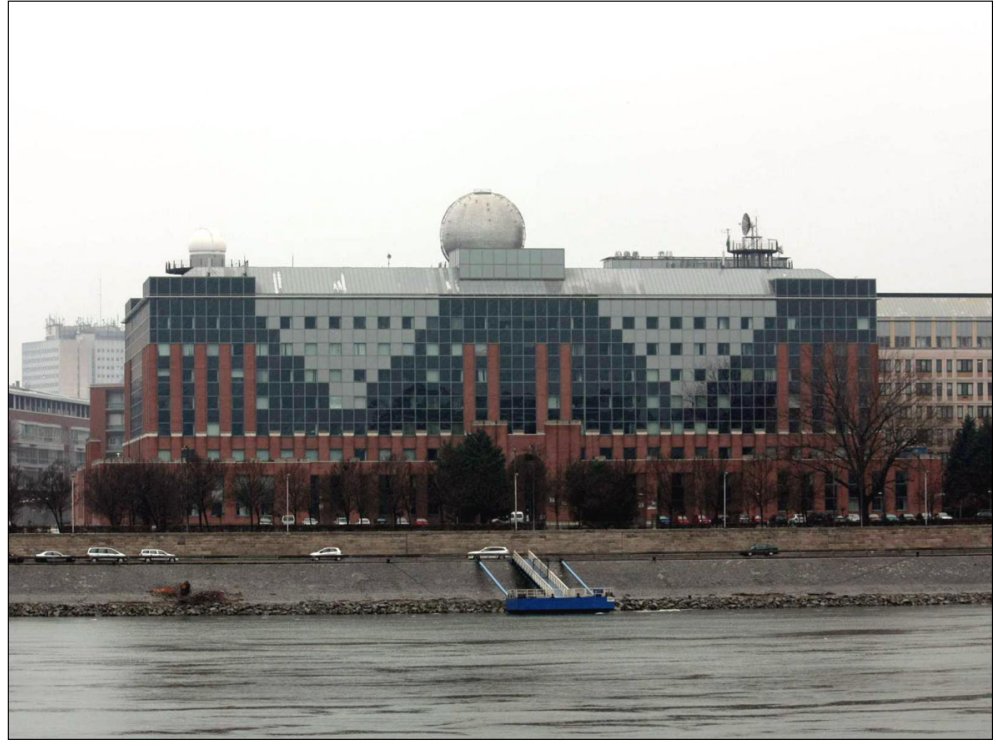

qualitatively the atypical feeding behaviour of $D$. major with that of the other four bird species observed earlier (Horváth et al. 2009; Robertson et al. 2010).

\section{Materials and methods}

We observed the feeding behaviour of a male and a female woodpecker (Dendrocopos major) from 5 to 12 May 2014 and from 5 to 22 May 2016, respectively. The observation was conducted every day between 16:00 and 20:00 h (= local summer time $=$ Universal Time Coordinated $+2 \mathrm{~h}$ ) at the northern building of the Faculty of Natural Sciences of the Eötvös University in Budapest $\left(47^{\circ} 29^{\prime} \mathrm{N}, 19^{\circ} 3^{\prime} \mathrm{E}\right)$, Hungary. The building is on the bank of the river Danube $100 \mathrm{~m}$ apart from the water. From north to the building there is a wooded land, which is the nesting area of the observed woodpeckers. We could not find the nest in the wooded area.

The building is $42 \mathrm{~m}$ high and $110 \mathrm{~m}$ wide. The lower third of the building is covered with red brickwork, while the remaining part is covered with shiny glass panels $(180 \mathrm{~cm} \times 180 \mathrm{~cm})$ of three different colours: dark grey (43\% of the wall surface), light grey (17\%), and common windows $(24 \%)$ with white curtains. These shiny surfaces,
Fig. 2 a, b Hydropsyche pellucidula caddisflies swarming in front of a dark (a) and a bright (b) glass pane of the building of the Eötvös University in Budapest (Hungary). c, d In the second part of their swarming, caddisflies (black dots) landed on the dark and bright glass surfaces. e, f A H. pellucidula on a glass pane of a window photographed from outside (e) and inside (f)

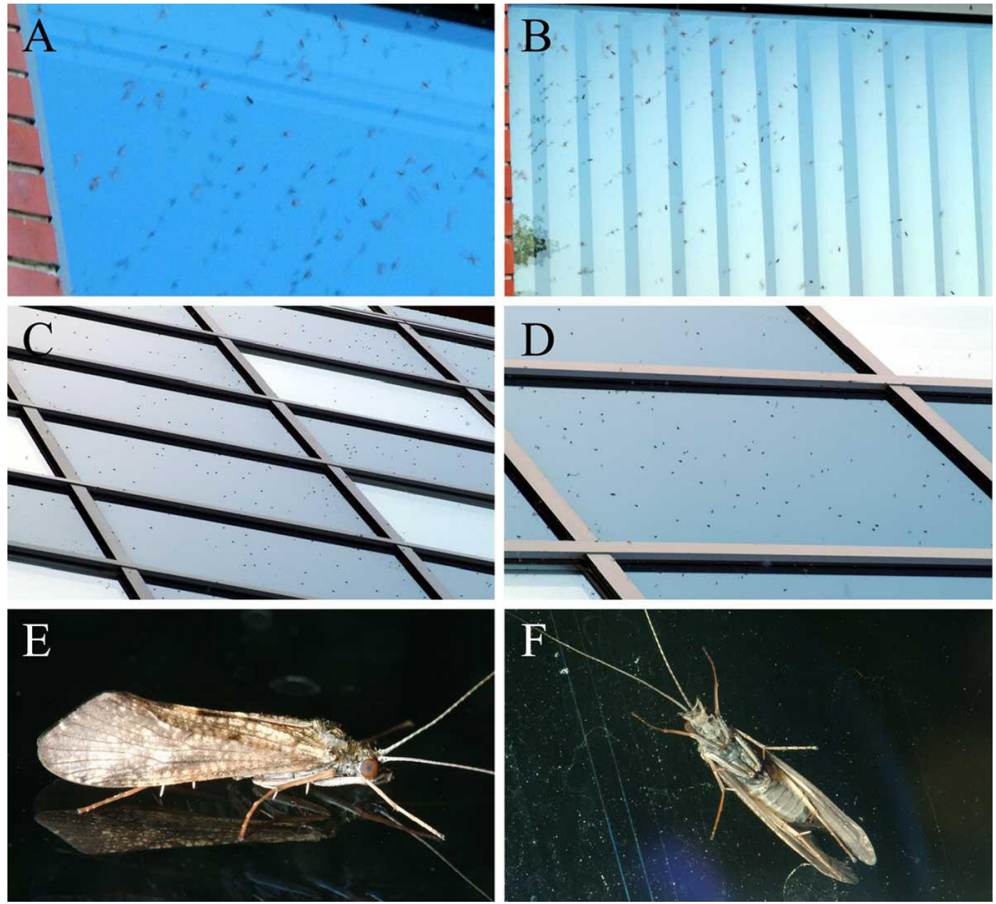


Fig. 3 Birds feeding on Hydropsyche pellucidula caddisflies attracted to glass surfaces of the building of the Eötvös University in Budapest. a, b A white wagtail (Motacilla alba) catching caddisflies in flight from a glass pane. c, $\mathbf{d}$ A magpie (Pica pica) sitting on a building's edge and picking caddisflies landed on the glass surface. e, $\mathbf{f} \mathrm{A}$ great tit (Parus major) sitting on a window's edge and gazing caddisflies swarming at the window

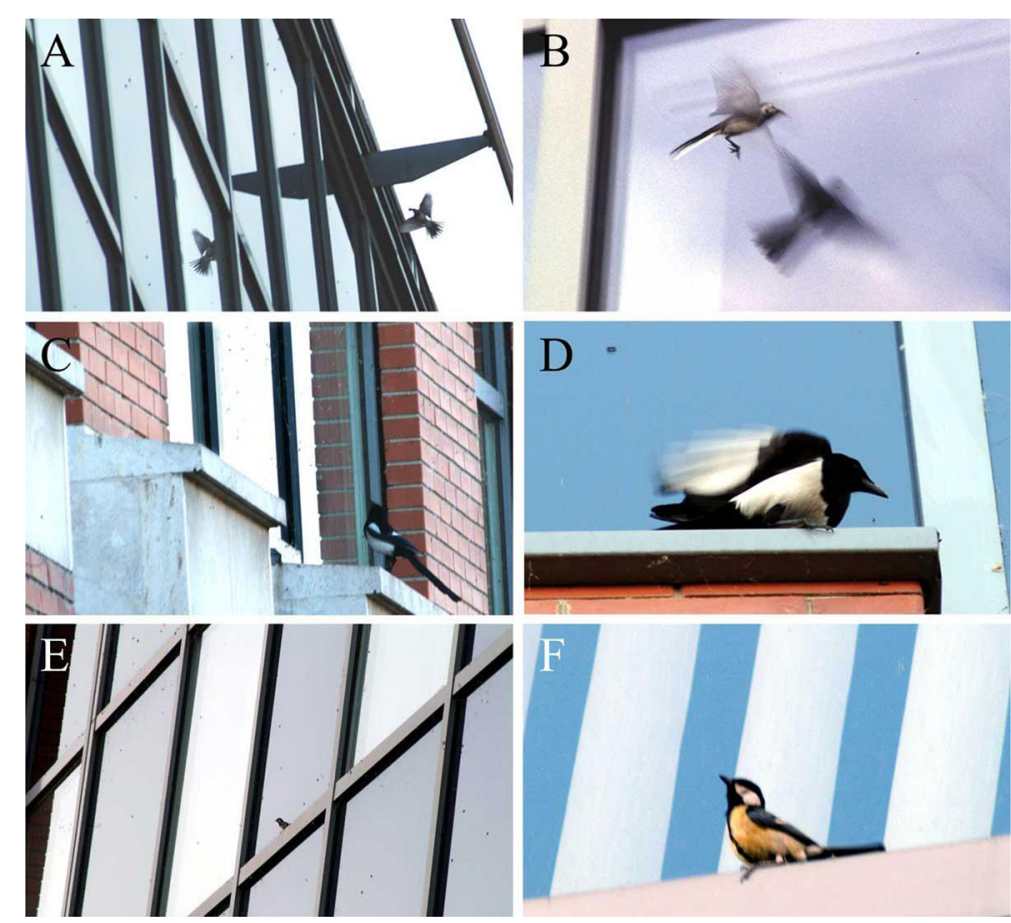

especially the dark greys, attract caddisflies (Kriska et al. 2008). There are 14 columns of bricks (in three groups) in the upper $2 / 3$ part of the building which are 7 panels high and 1 panel wide each (16\% of the surface) (Fig. 1). There are 150 windows in the upper $2 / 3$ part of the building. If the white curtain behind a window is drawn, the colour of the window is light grey, if the curtain is not drawn, the window colour is dark grey (Fig. 1). Usually, 25-35\% of the curtains are pulled together.

We made visual observations from the 2nd floor terrace which were documented with photographs. Each time, when birds appeared or flew away, photos were taken. The points of
Fig. 4 Birds feeding on Hydropsyche pellucidula caddisflies attracted to glass surfaces of a building of the Eötvös University (Budapest). a-c A male and $\mathbf{d}$ a female great spotted woodpecker,

Dendrocopos major crawling on the brick wall and feeding on the brickwork offering ideal landing sites. e A black redstart (Phoenicurus ochruros) picking caddisflies from glass panes. f A hooded crow (Corvus cornix) sitting on a window's edge and feeding on caddisflies
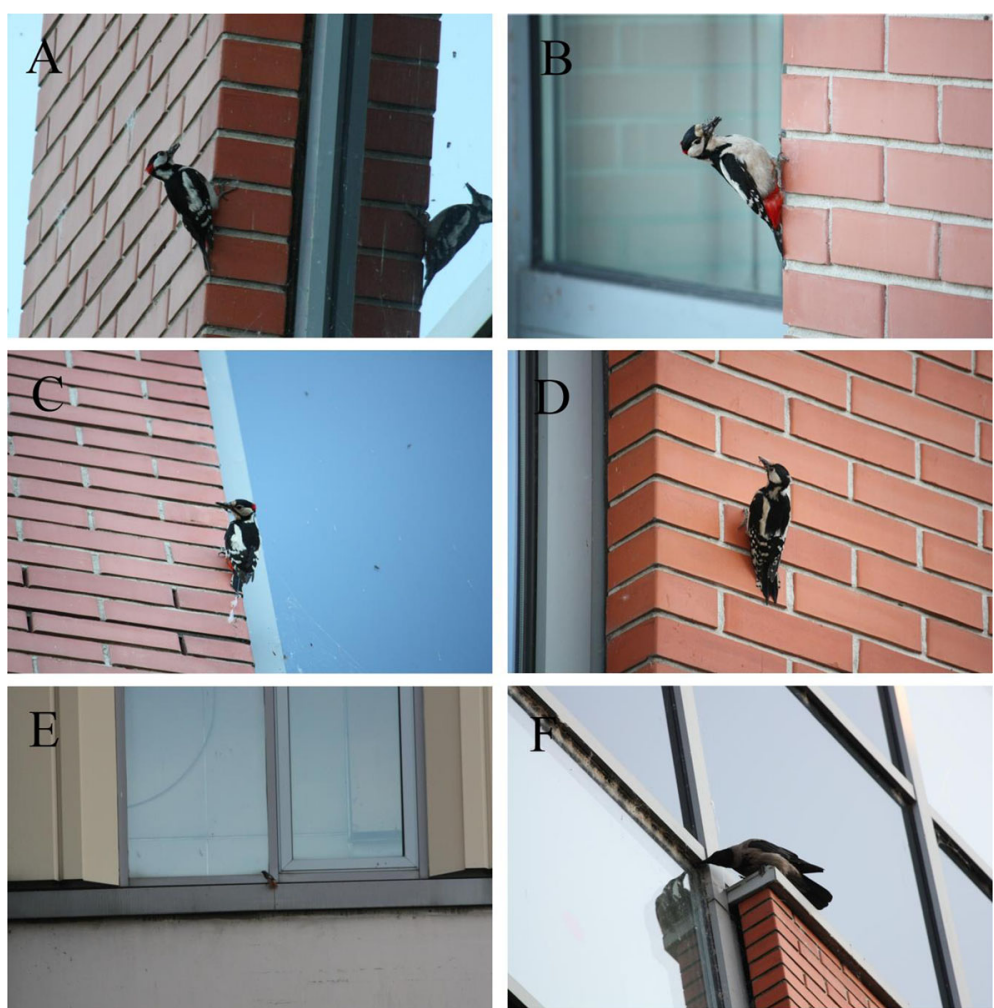
time of these events were extracted from the exif data of the photos.

Swarming caddisflies were observed at the building each year from 2006 to 2016. On 11 and 18 May 2016 we observed a pair of caddisfly-feeding hooded crow (Corvus cornix) and black redstart (Phoenicurus ochruros), respectively, at the buildings.

\section{Results}

Between 5 and 12 May 2014 we observed a male great spotted woodpecker consuming caddisflies on the building's walls (we could identify the specimen by its hardly used tail feathers). The woodpeckers landed on the brickwork. Some windows are framed with bricks which are perpendicular to the wall, and the woodpeckers were also able to hang on these bricks (Figs. 1 and 4a-d). Between 5 and 22 May 2016 we observed a female great spotted woodpecker feeding on caddisflies. On 2016 there was likewise only one specimen feeding at the building. Similarly to magpies, tits and sparrows observed earlier (Horváth et al. 2009; Robertson et al. 2010), the woodpeckers fed on the glass-attracted caddisflies in the evening between 19:00 and 20:00 h (Fig. 4a-d, Supplementary Video Clips 1-2). The woodpeckers visited the building only for feeding, they were never observed before 19:00 h. The woodpeckers were searching for food only on the east side of the building where caddisflies were the most abundant. The birds landed on the walls covered with brickwork near the dark windows. This way they could reach the caddisflies landed on the brickwork and the brink of the windows. We observed only this type of feeding. Hovering or jumping, for example, has never been noticed. Standing on the brickwork, the woodpeckers collected several caddisflies. After they had 3-4 caddisflies in their bill, they flew to a horizontal part of the building and released the already dead insects and then picked them up again. During this behaviour, the woodpeckers probably ingested some caddisflies, because then they often flew back to the brickwork and picked up further insects. Furthermore, 4-5 times per hour the woodpeckers flew away toward north to the wooded area with caddisflies in their bill. After the birds returned to the building, they continued their feeding in the north part of the eastern wall of the building. During our observations there were as many caddisflies on the wall as the woodpeckers could catch without moving. But the birds slowly flew and landed more and more southwards.

On 11 May 2016 we observed a pair of hooded crow (Corvus cornix) landing to the building's edge and picking up the caddisflies. Later the crows flew to the building's roof and looked for food there. On 18 May 2016 we observed a pair of black redstart (Phoenicurus ochruros) flying to the building's wall and feeding on caddisflies by hovering and jumping.

\section{Discussion}

The typical feeding behaviour of woodpeckers is drilling holes while foraging for insects. Török (1990) found that $D$. major is a generalist feeding almost exclusively on arthropods. Besides foraging insects, woodpeckers often feed on the ground, searching for nuts, eating suet, sapping, or carcasses (Kilham 1965; Selva et al. 2005). Earlier, woodpeckers have not been observed to consume aquatic insects attracted to glass surfaces. In this respect, this is an atypical feeding behaviour of woodpeckers.

In Budapest, the swarming season of $H$. pellucidula caddisflies lasts from the end of April to the middle of May. During this period the caddisfly pupae climb out from water and moult to imago on the riverbank. At the beginning of swarming the caddisflies aggregate in swarms containing about 50-200 specimens, becoming more and more abundant in the $100 \mathrm{~m}$ zone of the riverside. Buildings with a decorative strongly and horizontally polarizing dark glass ornament or dark windows can be the place of swarming for those caddisfly swarms, which aggregate far from the river. The dark silhouette of these buildings against the bright sky is well recognizable for caddisflies looking for appropriate swarming sites. For caddisflies flying at higher altitudes the sky does not help to recognize the dark buildings seen below the similarly dark subhorizontal region of their visual field. However, the strongly and horizontally polarized light reflected from glass surfaces of buildings constitute a striking visual signal in the usually weakly polarizing or unpolarized optical environment. This signal attracts polarotactic caddisflies (Kriska et al. 2008; Malik et al. 2008).

The observed building of the Eötvös University is covered by vertical dark grey and light grey decorative glass surfaces and possesses numerous windows which reflect strongly and horizontally polarized light that attracts polarotactic caddisflies (Fig. 2). We observed that caddisfly swarms are not formed at the weakly polarizing or unpolarizing bright (especially white) surfaces of the building. Kriska et al. (2008) showed that caddisflies preferred dark glass surfaces against bright ones (Fig. 2c-d): on dark glass surfaces 3-7 times more caddisflies landed than on bright ones.

House sparrows (Passer domesticus), great tits (Parus major), magpies (Pica pica), hooded corws (Corvus cornix), black redstarts (Phoenicurus ochruros) and woodpeckers (Dendrocopos major) could only capture caddisflies landed on glass panes or brick walls. Beyond this method, wagtails (Motacilla alba) were also able to catch caddisflies from the glass surfaces during their levitation flight in front of glass panes. At the beginning of swarming, caddisflies were flying almost exclusively in front of dark glass surfaces, and only a few of them landed on the glass itself. Therefore, in this early period only wagtails were able to catch large numbers of caddisflies in flight. In the second half of swarming (after 
17:00 $\mathrm{h}=\mathrm{UTC}+2 \mathrm{~h}$ ) female caddisflies landed on dark glass surfaces from which sparrows, great tits and magpies could also easily catch caddisflies. The bird species which were not able to capture flying caddisflies could feed from the swarming mass after the insects landed on the building. Tits, sparrows and magpies picked landed caddisflies from the edges and glass surfaces of the building. The observed woodpeckers approached the dark glass surfaces with the most abundant landed caddisflies by crawling in the brickwork. This feeding behaviour is similar to the natural one used on trees (Gorman 2004).

The swarming season (from the end of April to the middle of May) of $H$. pellucidula caddisflies observed at glass buildings on the bank of river Danube partly coincides with the breeding period of the observed woodpeckers. Thus, the caddisfly mass trapped at the glass buildings is an important food source for these birds, even if they are typically not feeding on caddisflies. The study of nutrition timing and feeding strategy of woodpeckers related to the swarming dynamics of caddisflies could be an interesting task of future research.

\section{References}

Gorman G (2004) Woodpeckers of Europe: a study of the European Picidae. Bruce Coleman, UK

Horváth G, Csabai Z (2014) Chapter 5: Polarization vision of aquatic insects. In: Horváth G (ed) Polarized light and polarization vision in animal Sciences, vol 2014. Springer, Heidelberg, Berlin, New York, pp 113-145

Horváth G, Kriska G, Malik P, Robertson B (2009) Polarized light pollution: a new kind of ecological photopollution. Front Ecol Environ $7: 317-325$

Kilham L (1965) Differences in feeding behaviour of male and female hairy woodpeckers. The Wilson Bulletin 77:134-145

Kriska G, Horváth G, Andrikovics S (1998) Why do mayflies lay their eggs en masse on dry asphalt roads? Water-imitating polarized light reflected from asphalt attracts Ephemeroptera. J Exp Biol 201:22732286

Kriska G, Csabai Z, Boda P, Malik P, Horváth G (2006) Why do red and dark-coloured cars lure aquatic insects? The attraction of water insects to car paintwork explained by reflection-polarisation signals. Proc R Soc Lond B 273:1667-1671

Kriska G, Malik P, Szivák I, Horváth G (2008) Glass buildings on river banks as 'polarized light traps' for mass-swarming polarotactic caddis flies. Naturwissenschaften 95:461-467

Malik P, Hegedüs R, Kriska G, Horváth G (2008) Imaging polarimetry of glass buildings: why do vertical glass surfaces attract polarotactic insects? Appl Opt 47:4361-4374

Robertson B, Kriska G, Horváth V, Horváth G (2010) Glass buildings as bird feeders: urban birds exploit insects trapped by polarized light pollution. Acta Zool Acad Sci Hung 56: 283-293

Schwind R (1991) Polarization vision in water insects and insects living on a moist substrate. J Comp Physiol A 169:531-540

Schwind R (1995) Spectral regions in which aquatic insects see reflected polarized light. J Comp Physiol A 177:439-448

Selva N, Jedrzejewska B, Jedrzejewski W, Wajrak A (2005) Factors affecting carcass use by a guild of scavengers in European temperate woodland. Can J Zool 83:1590-1601

Török J (1990) Resource partitioning among three woodpecker species Dendrocopos spp. during breeding season. Holarct Ecol 13:257-264 